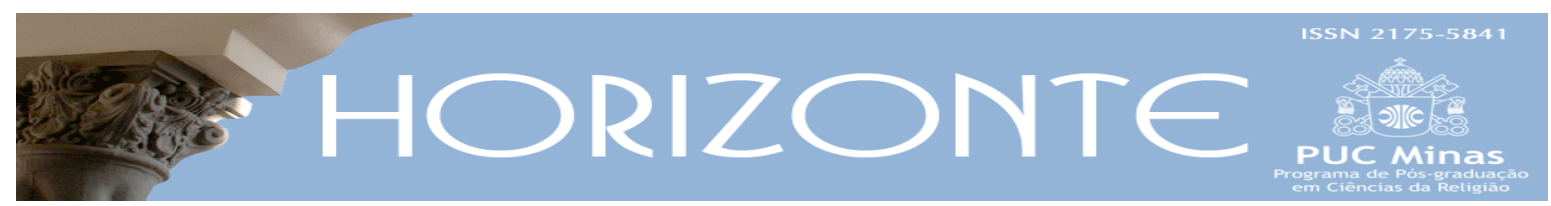

Dossiê: Religião, Direitos Humanos e Direitos da Natureza - Artigo Original ๑.

DOI - 10.5752/P.2175-5841.2017v15n47p828

\title{
Discursos religiosos e sociedade democrática
}

\section{Religious discourses and democratic society}

\author{
Alberto Paulo Neto* \\ Ildo Perondi*
}

\begin{abstract}
Resumo
O artigo investiga a pertinência dos discursos religiosos para a construção da sociedade democrática. Ele enfatiza a necessidade de reinserção normativa dos discursos religiosos com o objetivo de efetivar o ideal comum de direitos humanos. Este desígnio é apresentado mediante a investigação da contemporaneidade filosófica e a observação da contribuição das religiões para a realização do objetivo de fraternidade e solidariedade entre os cidadãos com distintas orientações axiológicas. A teoria do discurso de Jürgen Habermas analisa que as sociedades contemporâneas estão vivenciando o processo de pós-secularização e o ressurgimento das religiões na esfera pública. O filósofo alemão considera que as instituições religiosas têm o conteúdo normativo e a legitimidade que está ausente nas instituições políticas e nos atores políticos. As religiões mundiais se caracterizam pelas ações sociais e o incentivo à solidariedade aos seus fiéis. No nível pós-metafísico de fundamentação da forma política, os discursos religiosos podem motivar os cidadãos para a atitude comunicativa e o entendimento sobre as normas sociais que deverão reger a sociedade justa e inclusiva. Nesse sentido, a experiência de auto-esclarecimento das religiões sobre as suas doutrinas e princípios de fé poderá colaborar para o entendimento entre os cidadãos religiosos e não-religiosos. Por fim, a análise da experiência católica de autorreflexão sobre suas doutrinas e o relacionamento com as diversas religiões se tornou o exemplo de diálogo para as entidades religiosas no mundo secular.
\end{abstract}

Palavras-chave: Discursos religiosos, Teoria do discurso, Estado de direito, Democracia, Habermas, Direitos humanos.

\begin{abstract}
The article investigates the pertinence of religious discourses for the construction of a democratic society. He emphasizes the need for normative reinsertion of religious discourses in order to achieve the common ideal of human rights. This design is presented through the investigation of the philosophical contemporaneity and the observation of the contribution of the religions to the accomplishment of the objective of fraternity and solidarity between the citizens with different axiological orientations. Jürgen Habermas's discourse theory analyzes that contemporary societies are experiencing the post-secularization process and the resurgence of religions in the public sphere. The German philosopher believes that religious institutions have the normative content and legitimacy that is lacking in political institutions and political actors. The world religions are characterized by social actions and the encouragement of solidarity with their faithful. At the post-metaphysical level of grounding of the political form, religious discourses can motivate citizens to communicative attitude and understanding of social norms that should govern a just and inclusive society. In this sense, the experience of self-enlightenment of the religions on their doctrines and principles of faith can collaborate for the understanding between religious and non-religious citizens. Finally, the analysis of the Catholic experience of self-reflection on its doctrines and the relationship with the various religions has become the example of dialogue for religious entities in the secular world.
\end{abstract}

Keywords: Religious discourses, Discourse theory, Rule of law, Democracy, Habermas, Human rights.

\footnotetext{
Artigo submetido em 02 de julho de 2017 e aprovado em 24 de setembro de 2017.

* Doutor em Filosofia pela Universidade de São Paulo e realiza o estágio de pós-doutorado na Universidade de São Paulo com o Projeto de Pesquisa "Democracia contestatória e Justiça social". Líder do Grupo de Pesquisa "Justiça e Direitos fundamentais" (CNPq/PUCPR). Docente na Pontifícia Universidade Católica do Paraná (PUCPR). País de Origem: Brasil. E-mail: apnsophos@yahoo.com.br.

** Doutor em Teologia pela Pontifícia Universidade Católica do Rio de Janeiro (PUCRJ). Líder do Grupo de Pesquisa "Teologia e Sociedade" (CNPq/PUCPR). Docente e coordenador do curso de Teologia na Pontifícia Universidade Católica do Paraná (PUCPR). País de Origem: Brasil. E-mail: ildo.perondi@pucpr.br.
}

Horizonte, Belo Horizonte, v. 15, n. 47, p. 828-854, jul./set. 2017 - ISSN 2175-5841 
Ouso acreditar que as pessoas, em todas as partes, possam ter três refeições ao dia para os seus corpos; educação e cultura para as suas mentes; e dignidade, igualdade e liberdade para os seus espíritos (LUTHER KING JR, 2006, p. 69).

A religião é ameaçadora, inspiradora, consoladora, provocante, uma questão de rotina tranquilizadora ou de convite para colocar a vida em risco. É uma maneira de fazer a paz e uma razão para fazer a guerra (CALHOUN, 2011, p. 118).

Todas as religiões têm o dever de orientar as pessoas para a paz interior e exterior. Se queremos tornar este mundo melhor, precisamos tornar-nos pessoas melhores. Não há um caminho confortável. Em primeiro lugar, devemos ver os nossos inimigos como pessoas. Com Jesus, no Sermão da Montanha, isso significa "amar os nossos inimigos" (DALAI LAMA, 2015, p. 20).

\section{Introdução}

O artigo primeiro da Declaração Universal dos Direitos Humanos estabelece os princípios fundamentais para as sociedades democráticas contemporâneas: a defesa da igualdade de direitos e de liberdade e que o objetivo da sociedade política deveria ser a convivência em conformidade com o "espírito de fraternidade”. Nas sociedades democráticas desenvolvidas observa-se a garantia da isonomia e da ampla liberdade individual, todavia, elas carecem no suprimento da integração social que seja caracterizada pela solidariedade e fraternidade. É possível também dizer que historicamente as instituições religiosas têm se caracterizado como rede de solidariedade e que formam os cidadãos para a atuação em "espírito de fraternidade" na sociedade política. No entanto, essa valorização da ação social religiosa não possui a mesma aceitação em relação ao saber religioso como orientador das decisões políticas. A sociedade moderna estabeleceu a tentativa de restrição à influência religiosa no espaço público.

Assim permanecemos sob o antagonismo de valorização da atuação religiosa em prol da solidariedade e sua limitação. Esse artigo pretende abordar como os discursos religiosos podem colaborar para a construção da sociedade democrática. Além disso, apresentamos a experiência da Igreja Católica como forma de diálogo inter-religioso e de abertura ao procedimento democrático de discussão de caminhos para resolução dos problemas sociais. 
O filósofo alemão Jürgen Habermas (2012), em Nachmetaphysisches Denken II, investiga a relevância dos discursos religiosos na esfera pública e o teor de normatividade que as expressões religiosas podem aduzir para a fundamentação e defesa dos direitos humanos. A análise de Habermas está centrada em observar o fenômeno social de "pós-secularismo" nas sociedades desenvolvidas. Esse modelo de sociedade é procedente da concepção secularizante, iniciada na modernidade, mediante a separação das instituições religiosas e o poder político. A postura secularista estabeleceu que o Estado deveria ser neutro ideológico e religiosamente. No entanto, o processo de secularismo teria adentrado ao movimento dialético de retorno à religiosidade (novos movimentos religiosos de espiritualismo, ortodoxia moral e fundamentalismo) pela restituição da influência das religiões na esfera pública e estaria em conflito com a perspectiva laicizante das instituições políticosociais. A imagem da sociedade "pós-secular" concebe as religiões como “comunidades de interpretação" e assessoras ao procedimento de formação da opinião e da vontade pública.

A teoria do discurso de Habermas compreende a possibilidade de resolução de conflitos valorativos no plano político com o auxílio das religiões. Estas precisariam passar por um processo de auto-esclarecimento de suas doutrinas e a tradução de seus princípios axiológicos à inteligibilidade racional daqueles que não participam da mesma comunidade religiosa. Os discursos religiosos podem ter a função de amparar às decisões políticas na sociedade democrática. Nesse sentido, a inserção da forma de argumentação religiosa na esfera pública poderá estabelecer a estruturação da maneira de cooperação entre as instituições religiosas na construção de uma comunidade política mais justa e inclusiva.

Na epígrafe deste texto temos a apreensão paradoxal do fenômeno religioso. Ele expressa a possibilidade de ser observado como simultaneamente benéfico ou maléfico para a vida em sociedade. Esse antagonismo das religiões fez imergir severas críticas aos conteúdos semânticos das instituições religiosas e o desenvolvimento racional das diversas áreas do saber humano (moral, ciência, 
política, etc.) no período iluminista. Esse contraste entre fé e saber (conhecimento) permanece como sendo uma contenda infindável na existência humana. Por um lado, a perspectiva religiosa se intitula como sendo a forma ontológico-metafísica e fundacional do conhecimento humano e a orientadora primeira de todo conhecimento possível. Por outro lado, a perspectiva laicista pretende abolir o conhecimento religioso como integrante das diversas formas do conhecimento humano e romper com a fundamentação ontológico-metafísica de apreensão da realidade social.

A tensão entre a fé e o saber também repercute na vida política entre a cosmovisão religiosa de realização das decisões públicas e a normatização das instituições políticas, segundo os princípios religiosos, e a perspectiva secular de discussão pública sem uma orientação axiológica determinante e a acepção de normas sociais que possam ter o assentimento de todos os membros da sociedade política. Como veremos, os filósofos contemporâneos têm observado que as religiões mundiais salvaguardaram o conteúdo normativo de integração social e as sociedades capitalistas avançadas perderam a capacidade de coesão social pelas instituições políticas. Por isso, a necessidade de resgatar a normatividade das instituições políticas pelo auxílio do conteúdo normativo dos discursos religiosos.

Nesse sentido, devemos diferenciar a secularização do Estado, que se iniciou na modernidade com a separação do poder religioso e o político, e a secularização da sociedade como sendo a adoção de uma perspectiva laica (neutra) na vida privada e pública. Em verdade, o processo de modernização da sociedade não obteve o almejado efeito de declínio das formas religiosas de vida. Por isso, a relevância do estudo das religiões para a inserção correta das orientações religiosas aos princípios comuns à sociedade política.

Eduardo Mendieta e Jonathan VanAntwerpen (2011), no livro The power of religion in the public sphere, investigam a relação entre a vida pública e as crenças religiosas e diagnosticam a recente mudança nas pesquisas em ciências humanas sobre o âmbito religioso. As pesquisas acadêmicas (HABERMAS, 2012; 
BERNSTEIN, 2005; CASANOVA, 2013; MENDIETA \& VANANTWERPEN, 2011) apresentam as religiões como possuindo a significação pública. Os teóricos analisam que as pesquisas recentes não observam as religiões como restringidas ao domínio privado e os discursos religiosos podem ser traduzidos em discursos racionais para a orientação normativa da sociedade contemporânea.

Por exemplo, Habermas, seguindo a análise de José Casanova (1994) sobre a relação religião e esfera pública, argumenta que a perda de função pública e o processo de interiorização do fenômeno religioso não conduziram à redução da importância das instituições religiosas na sociedade secularizada ${ }^{1}$. As religiões, na modernidade, se mantiveram ativas na esfera política e cultural e na orientação da conduta pessoal dos projetos de vida. "Independentemente da sua importância quantitativa, as comunidades religiosas podem fazer valer a 'sede', mesmo na vida das sociedades amplamente secularizadas” (HABERMAS, 2015a, p. 267)².

Assim, Habermas estrutura o diagnóstico social da influência da religião na esfera pública sob duas perspectivas: externa e interna. A perspectiva externa do observador sociológico analisa que a religião manteve a sua influência pública na sociedade pós-secular e a dissipação do processo de laicização moderna. A perspectiva interna do participante observa o conteúdo normativo dos discursos religiosas. Os membros da sociedade pós-secular observam a necessidade de compreensão da comunidade política como espaço de desenvolvimento do "respeito civil” perante o crescente pluralismo ideológico e cultural. Como explica Verovšek (2017, p. 529):

Habermas endossa a religião na vida pública na medida em que expande as capacidades cognitivas e motivacionais dos indivíduos e das comunidades. No entanto, ele rejeita o sagrado como fonte de justificação pública. Habermas argumenta que o raciocínio baseado na fé deve ser articulado dentro das instituições do Estado somente após ter sido submetido à "tradução secular" em termos "pós-metafísicos", isto é, em linguagem acessível tanto para crentes como para não-crentes.

\footnotetext{
${ }^{1}$ A análise de Casanova (1994) demonstra a perenidade e a vitalidade da religião no mundo. O processo de modernização social teria se coadunado com o surgimento de novos movimentos e tradições religiosas (HABERMAS, 2015a, p, 109).

${ }^{2}$ A referência as sociedades secularizadas são exemplificadas pelos países da Europa Ocidental, Canadá e Austrália, Nova Zelândia.
} 
O discurso filosófico da modernidade não obliterou a possibilidade de entendimento entre as diversas modalidades de discursos racionais (éticos e teológicos) para o entendimento mútuo de temas e problemas que afetam os indivíduos na sociedade política. Prima facie o uso da metodologia do overlapping consensus (consenso por sobreposição), proposta por John Rawls, parece adequada para a busca de princípios comuns entre as instituições religiosas e as instituições sociais. Essa maneira de proceder argumentativamente na esfera pública poderá realizar o comprometimento dos cidadãos religiosos e não-religiosos com a defesa de uma sociedade mais democrática e justa. Essa metodologia precisa ser encaminhada mediante a discussão pública e não-coercitiva dos atores sociais que almejam pelo agir comunicativo o entendimento sobre as normas em geral. Nessa discussão pública deverá transparecer a defesa da pessoa humana como objetivo prioritário das instituições religiosas e sociais, a contribuição das religiões para a educação moral e a motivação para a prática do bem. Por consequência, o debate público poderá configurar em uma atitude de incentivo espontâneo à solidariedade e a fraternidade universal entre pessoas estranhas.

Nesse sentido, a discussão entre a razão pública e a razão teológica tem que se iniciar pela análise do movimento de secularismo na modernidade e a meta de restringir os discursos religiosos na vida pública dos cidadãos e investigar esse movimento secularista em um processo dialético de retorno e permanência das religiões no espaço público (1) e, por consequência, realizar a indagação sobre as maneiras de recepção dos discursos religiosos na sociedade complexa contemporânea (2). Por fim, observamos a experiência cristã de autoesclarecimento sobre as suas doutrinas e o diálogo com diversos saberes e cosmovisões (3).

\section{Secularismo, discursos religiosos e vitalidade das religiões}

A teoria da secularização denegou a relevância do conteúdo religioso para autocompreensão da sociedade moderna. Os saberes modernos (moral racional, direito moderno e a ciência experimental) foram decompostos dos elementos 
simbólicos e dos fundamentos transcendentes-normativos da religião (Cf. SOUZA, 2015, p. 278-9). O termo "secular" contrasta com o "religioso" porque possui a acepção de nominar o pertencimento ao "mundo" (saeculum) ou ao objeto que detém uma propriedade neutra em relação ao domínio religioso. Segundo José Casanova (1994, p. 14): “a divisão estruturada 'deste mundo' em duas esferas separadas: o 'religioso' e o 'secular' tem de ser distinguidas e separadas de outra divisão: entre 'este mundo' e 'outro mundo'”. O processo de secularização se constitui em um momento histórico de restrição da distinção medieval entre o mundo terreno e celestial. Por isso, o secular não se relaciona a divisão entre "este mundo" e "outro mundo", mas ele se refere ao horizonte conceitual de compreensão da mundanidade como única e apreensível pelo conhecimento científico ${ }^{3}$.

Se antes, era o reino religioso que parecia ser a realidade abrangente dentro do qual a esfera secular encontrou o seu devido lugar, agora a esfera secular será a realidade abrangente, para a qual a esfera religiosa terá de se adaptar (CASANOVA, 1994, p. 15).

Nessa perspectiva a dualidade metafísica, estabelecida platonicamente entre o mundo inteligível e sensível, perdeu a sua significação e adquiriu a forma monista de compreensão da realidade social. O processo de modernização social e de secularização obteve o êxito de realizar a diferenciação entre os sistemas sociais e restringir a atuação das comunidades religiosas à função pastoral (Cf. HABERMAS, 2012, p. 96-119; MENDIETA, 2010). As religiões tiveram reduzidas a sua importância e atuação na esfera pública. A prática religiosa foi destinada ao plano individual e subjetivo.

Em outras palavras, a religião se constituiu como uma faceta da vida privada e perdeu a relevância na esfera pública. A diferenciação entre sistemas sociais e

\footnotetext{
${ }^{3}$ Peter Berger formulou a hipótese que o processo de secularização e modernização social conduziria ao declínio do fenômeno religioso na sociedade ocidental e da influência religiosa nas instituições sociais (BERGER, 1985, p. 119). Recentemente, Berger (1999; 2013) reformulou esta hipótese e teve que afirmar a existência do processo de "dessecularização" do mundo e o retorno das instituições religiosas ao espaço público. Assim também, Joas (2009, p. 310) descreveu o retorno das religiões ao mundo político como sendo o "fim da secularização".
}

Horizonte, Belo Horizonte, v. 15, n. 47, p. 828-854, jul./set. 2017 - ISSN 2175-5841 
mundo da vida pode ser denotada como a delimitação entre o âmbito individual e o interiorizado. A diferenciação funcional dos subsistemas sociais significa a perda do controle religioso sobre os sistemas sociais e também a sua restrição funcionalística.

A partir desta perspectiva de análise do desenvolvimento da modernidade é possível compreender a "teoria da secularização" como relacionada ao processo de racionalização social entre sistema social e mundo da vida. Como explica R. Bernstein (2005, p. 197-198), mediante o viés de J. Casanova, as diferentes conotações do termo "secularização":

A ideia básica é que no curso do desenvolvimento moderno cada uma dessas esferas se tornara diferenciadas e relativamente autônomas, sob a reserva dos seus próprios procedimentos, normas e regularidades. Um segundo aspecto das teorias de secularização é a tese do declínio da religião. Esta é a afirmação de que, com o processo histórico de secularização desenvolve-se um declínio da religião. [...] Um terceiro aspecto é o declínio do papel público da religião - religião é privatizada. Torna-se uma questão de fé pessoal e é removida da esfera pública.

O primeiro aspecto representa a autonomização dos sistemas sociais em relação à tutela da religião. O segundo aspecto é deduzido do processo de racionalização social como a bancarrota das crenças religiosas em comparação com o processo de desenvolvimento humano. O terceiro aspecto é apresentado como a “privatização da religião" e questionado por J. Casanova (1994; 2013, p. 66) a partir de uma perspectiva empírica e normativa de permanência da religião na esfera pública. R. Bernstein (2005) questiona a pertinência desses três aspectos da teoria da secularização, principalmente a tese de declínio da religião, quando contraposta a realidade social de permanência e difusão da religião na sociedade moderna.

Por isso, as teorias contemporâneas das ciências humanas têm observado uma inflexão na forma de análise do fenômeno religioso como vivaz no espaço público e que o teor normativo das instituições religiosas necessita ser direcionado para a reestruturação normativa da vida pública. 
J. Habermas (2012, p. 308) argumenta que a sociedade europeia estaria adentrando a perspectiva pós-secular de compreender o papel da religião na esfera pública. A definição de "pós-secularidade” denota a ideia de que os cidadãos vivem em uma sociedade que passou pelo processo de secularização, iniciado na modernidade, e observam a relevância das religiões na organização dos projetos de vida na sociedade moderna. "A postura pós-secular olha para as fontes religiosas de sentido e motivação tanto como um aliado útil e mesmo indispensável para enfrentar as forças do capitalismo global, enquanto sublinha a diferença fundamental entre fé e conhecimento” (MENDIETA \& VANANTWERPEN, 2011, p. 04).

As religiões permaneceram com a sua vivacidade social durante o processo de modernização e seria possível elencar três fenômenos que caracterizariam essa expressividade das religiões: a expansão missionária das religiões na África e na Ásia, a radicalização fundamentalista e a instrumentalização política do conteúdo religioso.

O diagnóstico de Habermas ressalta que as comunidades religiosas mantiveram o seu posto de influência no espaço público e concomitantemente afastou a perspectiva "laicística" da modernização social. O filósofo alemão considera a resposta laicista de banimento da religião na arena pública com sendo uma forma de contradição na estrutura política dos Estados constitucionais. Pois a comunidade religiosa desempenha o papel vital na esfera pública e a censura à voz dos religiosos, no mesmo lugar onde deveria nascer e formar a sua vontade democrática (an der Quelle der Demokratischen Willensbildung), é obliterar o verdadeiro sentido das constituições liberais (HABERMAS, 2012, p. 183). De fato, Habermas argumenta que a teoria social contemporânea estaria realizando a mudança na autocompreensão da modernidade sob a interligação entre os elementos de fé e razão para corrigir os erros do extremo laicismo (cientificismo) das relações sociais. O uso da terminologia “sociedade pós-secularizada” denota a ideia de mudança de consciência nas sociedades secularizadas em três fatores: 
1) A vida em uma sociedade laica transformada pelo processo de modernização social e cultural não significou a redução do sentido público e pessoal da religião; 2). A influência religiosa na esfera pública tem se mostrado de maneira contínua e decisiva para a formação da opinião pública. Por isso, Habermas defende a tese que as religiões se transformem em "comunidades de interpretação" das aporias sociais e de temas polêmicos na esfera pública. Os discursos religiosos atuariam como auxiliadores na resolução de conflitos valorativos no plano político; e 3) O processo migratório, o pluralismo das formas de vida e a globalização do mercado de trabalho têm conduzido à tentativa de realização da convivência tolerante entre as diversas orientações religiosas.

De acordo com Habermas, a expressão “pós-secular” denota a permanência do status de sociedade secularizada e a consciência da ilusão que era o secularismo extremado, este como forma de negação da importância da religião na sociedade. A expressão "pós-secular” se refere ao uso sociológico para a descrição das sociedades modernas que se relacionam de forma inclusiva com as comunidades e tradições religiosas. O conceito de "sociedade pós-secular" se refere à mudança de mentalidade dos cidadãos secularizados em relação aos cidadãos religiosos. Por exemplo, a possibilidade de diálogo e entendimento entre a perspectiva científica e religiosa sobre os problemas sociais (Cf. HABERMAS, 2015a, p. 109)4. Como explica Bortolini (2017, p. 583):

Ao avançar a sua visão de uma "sociedade pós-secular", ele pediu aos cidadãos religiosos e não-religiosos que colaborem no fortalecimento das bases morais das instituições político-jurídicas modernas através do diálogo contínuo destinado a traduzir o patrimônio religioso, suas formas simbólicas, seu discurso e suas práticas, em argumentos racionais compartilhados.

\footnotetext{
${ }^{4}$ Como esclarece Ungureanu \& Monti (2017), a postura teórica de Habermas adota a perspectiva de mediação entre o saber religioso e a prática política. "Habermas propõe uma posição intermediária entre duas visões opostas e extremas sobre o lugar da religião nas democracias contemporâneas: a 'vingança de Deus', por um lado, e o inevitável divórcio da democracia e a religião, por outro. Sua visão de uma sociedade pós-secular tenta, em vez disso, reconciliar a tradição do lluminismo e a religião moderna, a democracia e a fé reflexiva" (UNGUREANU \& MONTI, 2017, p. 521).
}

Horizonte, Belo Horizonte, v. 15, n. 47, p. 828-854, jul./set. 2017 - ISSN 2175-5841 
Nesse sentido, as comunidades religiosas podem oferecer a argumentação convincente para autocompreensão normativa dos cidadãos em uma sociedade pluralista e funcionar como uma caixa de ressonância para a resolução de conflitos valorativos no plano político. Essa mudança de mentalidade resultou na concepção de que a vida em uma sociedade secular não significa a redução do sentido público e pessoal da religiosidade, as religiões prosseguem em sua relevância na esfera pública e podem ser compreendidas como "comunidade de interpretação" e exercerem a influência na formação da opinião e da vontade pública.

Esses fatores manifestam a dialética no projeto iluminista de secularização social e reestabelece a imprescindibilidade da recepção dos conteúdos normativos das instituições religiosas na esfera pública para a orientação axiológica dos cidadãos religiosos e não-religiosos. As instituições religiosas podem se constituir em um espaço para a orientação moral dos cidadãos e de motivação para a participação na vida pública. Ademais, elas se constituíram historicamente como o locus primário de realização da solidariedade e a fraternidade entre estranhos e de restituição da dignidade social dos indivíduos como pessoas humanas. Por exemplo, M. Bortolini (2017, p. 590) apresenta a relação de hospitalidade no continente asiático entre os monges de denominações religiosas diferentes como sendo a maneira de realização da prática comunicativa.

O reconhecimento do primado da partilha de práticas como meio para o desenvolvimento de disposições comuns é o núcleo do chamado "giro pragmático" no diálogo inter-religioso e nas iniciativas educacionais. Embora diferente em espécie e abrangente do projeto pós-secular habermasiano, as práticas contemporâneas inter-religiosas de hospitalidade e troca podem ser usadas como modelos exemplares desse tipo de trabalho e como uma indicação do que pode ser alcançado através do estabelecimento de práticas cooperativas similares entre cidadãos religiosos e não-religiosos. Entre muitos exemplos, o trabalho pioneiro dos monges beneditinos, entre os quais Thomas Merton continua a ser uma figura imponente, é talvez o mais visível e convincente. Como um antigo secretário do Diálogo Inter-religioso Monástico, fundado pela Igreja Católica para promover o intercâmbio entre monges cristãos e freiras e religiosos e religiosas de outras confissões, Pierre-François de Béthune, OSB tem estado na vanguarda dos encontros inter-religiosos desde 1979 (BORTOLINI, 2017, p. 590).

Horizonte, Belo Horizonte, v. 15, n. 47, p. 828-854, jul./set. 2017 - ISSN 2175-5841 
Bortolini revela que a prática de convivência e aprendizagem entre os monges beneditinos e os zen budistas são fruto da relação dialógica e da compreensão do valor do outro como ser humano e divino. Ademais, poderíamos analisar as diversas entidades religiosas que realizam ações sociais e de cuidado com o próximo como sendo originárias da prática religiosa e da autocompreensão que os religiosos têm de si (Cf. HABERMAS, 2012, p. 120; 127).

\section{0 ponto de inflexão no secularismo: 0 retorno da religião ao espaço público}

A sociedade "pós-secular" refere-se às sociedades europeias secularizadas que observam a sobrevivência tenaz de formas pré-modernas do pensamento e contradiz a perspectiva secularista. Esta não admite o conteúdo do pensamento religioso na esfera pública. A consciência pós-secular dos cidadãos tem a compreensão da necessidade de estabelecimento da comunidade política inclusiva e o desenvolvimento do "respeito civil" perante o crescente pluralismo cultural.

O princípio de separação da igreja e do Estado como forma de secularização do poder estatal, se constituiu como a resposta adequada as guerras religiosas no início da modernidade. Ele objetivou garantir os direitos individuais de culto e liturgia às minorias religiosas e constituiu o Estado como mantenedor da ordem pública. $\mathrm{O}$ aparato estatal assumiu a postura de neutro perante a diversidade religiosa.

Segundo Habermas (2015a, p. 268-270), as revoluções constitucionais do século XVIII criaram a ordem política sujeita simultaneamente ao poder político secularizado e impessoal. O Estado constitucional seria regido pelo princípio da soberania popular. Ele garante a liberdade religiosa pela aceitação entre os cidadãos para a criação do horizonte de socialização e a integração da comunidade religiosa. Os cidadãos seculares e religiosos atribuem-se as leis para a proteção e o respeito da identidade cultural. O Estado democrático de direito se estabelece pela aplicação imparcial do princípio da liberdade religiosa. Esse princípio se impõe como direito individual e exige o respeito e a igual consideração aos membros da 
comunidade política.

De acordo com Habermas (2015a, p. 270-272), as razões para tolerância religiosa devem ser resultado de procedimentos democráticos e da formação deliberativa da vontade política. O princípio de tolerância não é somente uma questão jurídica de fundamentação e aplicação das leis, ele deve ser aplicado em todas as áreas da vida. Os cidadãos religiosos e não-religiosos devem se concederem a possibilidade de vida social sob a hipótese de ideias, práticas, formas de vida que a eles pessoalmente acreditam ser repugnantes. Essa "concessão" pode ser a base comum de "reconhecimento mútuo" na sociedade democrática. A forma de reconhecimento admite que seja desconsiderada as dissonâncias que impedem o entendimento comum. $\mathrm{O}$ ato de reconhecimento não é a aceitação positiva das crenças e práticas que são consideradas abjetas, mas ele é a condição de possibilidade para que a prática religiosa estranha tenha a mesma garantia de direitos que a prática religiosa hegemônica. A tolerância se refere aos hábitos e prática religiosas que prima facie parecem ser repugnantes. A base do reconhecimento (Anerkennungsbasis) é a consciência de ser parte de uma comunidade inclusiva. Nesta comunidade política cada cidadão apresenta a justificação do uso de suas expressões e ações políticas em argumentos racionais inteligíveis.

Esse modelo de integração social possui a ideia de sociedade inclusivista que harmoniza a igualdade política e as diferenças culturais. Ele possibilita que as minorias étnicas-religiosas participem no processo político de inclusão igualitária e equiparação jurídica. Como explica ZAMBAM \& AQUINO (2015), a tolerância se tornou o requisito para a vida moderna com qualidade e a saída das relações sociais de menosprezo e humilhação ou dominação no contato com o outro.

A Tolerância surge como um valor moral para o aperfeiçoamento histórico das sociedades democráticas. Em uma época de alta relatividade - social, axiológica, econômica, política, jurídica, entre outros -, experimenta-se uma convivência vazia, na qual nada é duradouro ou, pelo menos, aparece com a finalidade de "salvar a humanidade" de sua natureza violenta, mesquinha (ZAMBAM \& AQUINO, 2015, p. 367). 
No âmbito jurídico o princípio da tolerância se estabelece como dever normativo de respeito aos direitos individuais. Ele se fundamenta pela universalidade de seus destinatários e requer a obrigação jurídica aos membros da comunidade política. A adoção da universalidade dos princípios políticos é necessária para identificação dos preconceitos que possam viciar a interpretação constitucional culturalmente majoritária. A norma constitucional deve ser formulada e justificada em uma linguagem acessível. A neutralidade do Estado não proíbe a admissão do conteúdo religioso na esfera pública política. No entanto, os procedimentos institucionais de tomada de decisão se estabelecem como distintos da participação informal dos cidadãos na comunicação e formação de opinião pública. Assim sendo, a separação entre o Estado e a igreja permanece como filtro que as "agendas" das instituições políticas formais continuam sendo traduzidas para a linguagem secular.

Nesse sentido, os cidadãos seculares e religiosos concederam viver sob ideias, práticas, formas de vida que a eles podem ser pessoalmente repugnantes, mas que se obrigam ao igual respeito e consideração. Essa "concessão" seria a base comum de "reconhecimento mútuo" das dissonâncias na sociedade moderna. Esse reconhecimento não pode ser entendido como a aceitação positiva de crenças e práticas que continuam a ser julgadas estranhas.

A base de reconhecimento (Anerkennungsbasis) é a consciência de pertencimento à comunidade política inclusiva. Nesta sociedade política, os cidadãos fornecem a justificação de suas expressões e ações políticas. A inclusão igualitária seria caracterizada por uma cultura política que garanta os direitos individuais e propicia as condições materiais de integração.

Habermas afirma que a prática inclusiva na esfera política exige que a cultura política não seja insensível às diferenças sociais ao conceder o espaço de ação livre dos cidadãos religiosos, ela deve garantir os recursos e condições materiais para integração social. Neste caso, a sociedade política multicultural concede oportunidades aos membros estrangeiros para que tenham a possibilidade 
de equalizar as desvantagens sociais em relação aos cidadãos nativos.

\begin{abstract}
A inclusão homogênea de todos os cidadãos, desde a perspectiva da sociedade civil, não somente exige uma cultura política que se preserve de confundir a liberalidade com a indiferença. Ela só pode lograr quando cumpre também determinados requisitos materiais, entre outros, a integração na creche, na escola e na universidade, na medida em que nivele as desvantagens sociais e o acesso ao mercado de trabalho com as mesmas oportunidades. Entretanto, no nosso contexto é importante, sobretudo, a imagem de uma sociedade civil inclusiva que complementa de maneira correta a igualdade cidadã e a diferença cultural (HABERMAS, 2015a, p. 272).
\end{abstract}

Segundo esta perspectiva normativa existiria um paradoxo na sociedade liberal em relação às religiões porque esse modelo de sociedade suporta a existência das religiões e simultaneamente não admite que os discursos religiosos possam colaborar na autocompreensão da contemporaneidade (Cf. HABERMAS, 2015a, p. 273-274). Habermas adotou a postura teórica que observa as religiões como colaboradoras na formação política da opinião e da vontade. Para ele seria possível a obtenção reflexiva da consciência religiosa pelo modelo de transformação cognitiva interna aos membros da comunidade religiosa e o uso deste conteúdo normativo nas instituições políticas.

Essa transformação auto-esclarecida dos princípios religiosos não pode ser imposta pela via estatal ou ser juridicamente prescrito. Ela é o resultado do processo de aprendizagem mediante a autocompreensão normativa das ideias, crenças e princípios que embasam a religiosidade. Assim, os processos de aprendizagem podem ser promovidos e incentivados pela sociedade civil e comunidade religiosa, mas eles nunca devem ser reivindicados como obrigatório moral ou juridicamente.

Os processos de aprendizagem podem ser aplicados tanto ao tradicionalismo religioso como a perspectiva secularizante. Segundo Habermas (2015a, p. 278), a inclusão cívico-democrática possuiria cláusulas que proibiriam os cidadãos nãoreligiosos de desacreditarem as doutrinas religiosas que não estejam em conflito com os direitos humanos. O filósofo alemão acredita que existiriam duas razões 
para apoiar esta abertura ao normativismo religioso: o uso da capacidade cognitiva de distinguir os vocabulários e convicções em um componente profano e religioso para a participação no processo de formação de vontade política e a necessidade das instituições políticas não reduzirem a complexidade polifônica das diversas vozes públicas e recorrerem aos recursos normativos para a fundação da identidade coletiva.

A sociedade secular não pode excluir a priori o poder do conteúdo semântico interno às contribuições religiosas e este conteúdo pode ser traduzido em termos de argumentação pública. As tradições religiosas possuem os recursos para a articulação da sensibilidade (motivação) moral e os insights de solidariedade que estão ausentes na sociedade moderna.

O diagnóstico sobre a religião na esfera pública realizado por J. Habermas parece compreender que as instituições religiosas não enfraqueceram a sua vitalidade com o processo de modernização e que o normativismo religioso pode ser traduzido em uma linguagem pública.

As práticas religiosas e perspectivas, conclui Habermas, continuam a serem as principais fontes dos valores que nutrem uma ética de cidadania multicultural, comandando tanto a solidariedade e o igual respeito. No entanto, para que os "potenciais semânticos vitais das tradições religiosas" possam ser disponibilizados para a cultura política mais ampla (e, em particular, no âmbito das instituições democráticas), eles devem ser traduzidos para uma linguagem secular e uma "linguagem universalmente acessível", uma tarefa que cabe não só aos cidadãos religiosos, mas a todos os cidadãos, tanto religiosos e seculares - que se dedica ao uso público da razão (MENDIETA \& VANANTWERPEN, 2011, p. 04-05).

O conteúdo normativo das religiões pode se tornar um motivo para a realização de ações de solidariedade aos indivíduos que não comungam dos mesmos princípios religiosos sob o pretexto de ser uma pessoa humana com direitos inalienáveis. Além disso, as tradições religiosas podem incentivar à participação política e a democratização das instituições públicas mediante a aceitação da petitio principii de tradução do conteúdo religioso em uma linguagem acessível e autorreflexiva para todos os membros da sociedade política. 
Essa competência política se institui como dever a todos os cidadãos (religiosos ou não-religiosos) em sua inserção na esfera pública pela via da argumentação. Nesse sentido, a exigência de tradução do conteúdo religioso não se constitui em uma determinação de posição hierárquica superior aos cidadãos religiosos, ela é a conditio sine qua non para o entendimento mútuo entre todos os participantes da vida pública.

Habermas observa que a experiência do Concílio Vaticano II proporcionou à Igreja Católica a internalização da legitimidade secularizada da comunidade política em suas próprias premissas de fé. Assim como, Rawls, Habermas argumenta que a doutrina católica adquiriu a forma do liberalismo democrático e se tornou uma “doutrina abrangente" e "compreensiva”. Isso quer dizer que o catolicismo passou por um processo internalização das premissas políticas que estabelecem o Estado democrático de direito e os procedimentos democráticos. Como esclarece Habermas:

Também os cidadãos religiosos e as comunidades religiosas devem adaptar-se não somente de forma externa. Tem que fazer a sua legitimação secular do Estado, desde as premissas de sua própria fé. Como todo mundo sabe, a Igreja Católica não se declarou a favor do liberalismo e da democracia até o ano de 1965, com o Concílio Vaticano II (HABERMAS, 2015a, p. 276-277).

O filósofo estadunidense, John Rawls, foi mais enfático ao valorizar a experiência do Concílio Vaticano II como sendo a transformação da doutrina católica em doutrina abrangente e a capacidade de produzir a compreensão normativa sobre as instituições políticas. Como explica Álvaro de Vita:

Rawls introduz em $O$ liberalismo político o argumento de que essa concepção política só poderá assegurar a estabilidade, no sentido que aqui é relevante, se os adeptos de diferentes 'doutrinas abrangentes razoáveis' puderem afirmá-la da ótica dessas estruturas normativas mais amplas que professam. Por exemplo, os cidadãos que professam uma doutrina religiosa que aceita uma noção de fé livremente professada encontrariam razões para afirmar a concepção política que derivam da sua própria doutrina abrangente. A noção de tolerância, nesse caso, não é puramente 
política, e sim se expressa de dentro de uma doutrina religiosa. Quando isso é possível, Rawls supõe que uma doutrina abrangente seja 'razoável' e que esse é o caso do Catolicismo Romano, desde o Concílio Vaticano II, e de certas formas de Protestantismo, Judaísmo e Islamismo. Neste último caso, Rawls empenha-se em mostrar, em uma longa nota de rodapé no ensaio 'The idea of public reason revisited', que há uma interpretação da Sharia que a torna compatível com o apoio a uma democracia constitucional" (VITA, 2009, p. 73).

A análise rawlsiana, segundo Vita (2009), observa que as doutrinas religiosas que se tornaram "doutrinas abrangentes e razoáveis" podem colaborar com a estabilidade política e a união social. Em outras palavras, as religiões mundiais possibilitariam o entendimento da normatividade do Estado democrático de direito. Rawls (1999, p. 149-150), no artigo “A ideia de razão pública revisitada”, considerou a realização do Concílio Vaticano II e os movimentos sociais e religiosos de luta por igualdade dos direitos civis nos EUA, liderado por Martin Luther King $\mathrm{Jr}$, como sendo a forma de exercício do alinhamento dos princípios religiosos aos princípios políticos do Estado constitucional. Por exemplo, o Concílio Vaticano II asseverou o princípio da liberdade religiosa como necessário para a vida humana em uma democracia. $O$ discurso religioso ofereceu a fundamentação normativa desse direito humano por meio da defesa da dignidade e a aceitação dos limites de atuação da instituição religiosa. Nesse sentido, iremos analisar a experiência cristã católica sobre o diálogo inter-religioso e o ecumenismo para a busca da fraternidade na sociedade moderna.

\section{A experiência cristã como exemplo de diálogo}

O cristianismo, em suas diferentes denominações, sobretudo nos últimos tempos, procurou dar uma resposta à questão da sua relação com mundo, bem como o diálogo inter-religioso. Na Igreja Católica verificou-se uma abertura maior a partir do Concílio Vaticano II (1962-65) e já fruto das reflexões teológicas que o antecederam. Alguns documentos importantes do Concílio impulsionaram este objetivo: A Constituição "Gaudium et Spes" (GS), que trata da relação da Igreja com o mundo; o Decreto "Unitatis Redintegratio" (UR) que apresenta uma 
proposta para o diálogo ecumênico com as demais denominações cristãs; e a Declaração "Nostra Aetate" (NA) que propõe o caminho para o diálogo com as outras religiões não cristãs.

A Igreja Católica preocupada com o que acontece com "das questões que envolvem o homem do berço ao túmulo, como são as sociais e sócio-políticas" (JOÃO PAULO II, 1986, p. 2), esteve atenta e procurou se inserir no mundo com o objetivo de cooperar na construção de uma sociedade mais justa e fraterna. É o que se vê já na abertura da Gaudium et Spes:

As alegrias e as esperanças, as tristezas e as angústias dos homens de hoje, sobretudo os pobres e de todos os que sofrem, são também as alegrias e as esperanças, as tristezas e as angústias dos discípulos de Cristo. Não se encontra nada verdadeiramente humano que não lhes ressoe no coração (GS 1).

Constata-se que a sociedade atual é marcada por uma contradição quando o fenômeno religioso é analisado. É certo que estamos diante de um mundo secularizado, que busca sua própria autonomia e constrói Estados laicos. Isso, no entanto, não quer significar a ausência do fenômeno religioso, pois justamente diante da fragmentação da vida moderna, o ser humano tem necessidade e busca as mediações religiosas. O religioso se manifesta na experiência humana e na convivência social das pessoas e não se pode negar a sua contribuição na formação do seu tecido social. Neste sentido, verifica-se uma busca do Transcendente por parte do ser humano e ao mesmo tempo uma busca humana por parte do Transcendente que se revela. Deus é o Transcendente que se comunica. Segundo a tradição cristã, o Transcendente se torna presente em nossa imanência. É este o significado da encarnação Jesus de Nazaré na realidade humana, é a humanização de Deus, que vem até a nós para dialogar e comunicar seu projeto.

A fé cristã exige necessariamente o comportamento ético, seja em relação às pessoas como ao todo da Criação. O cristianismo não se fundamenta na observância de um conjunto de normas e leis, mas na vivência prática da fé e que se manifesta em comportamentos e atitudes éticas e vivenciais a serviço da vida, não 
somente em relação às pessoas próximas, mas com todas as pessoas e com o futuro do nosso planeta. E então é importante fazer com que esta fé se traduza numa convivência de tolerância, na prática de justiça, da misericórdia e da caridade. Uma ética que abrange todo agir humano baseado no respeito e com o compromisso da construção de uma sociedade nova, justa e fraterna.

A Igreja deseja permanecer fiel à mensagem anunciada por Jesus Cristo, cujo projeto tinha um nome: o Reino de Deus. A proposta do Reino envolve o ser humano no seu todo. A Igreja, como servidora do Reino, coloca-se a serviço da humanidade no sentido de trazer sentido à vida do ser humano. A Igreja reconhece que as religiões têm um papel fundamental no mundo sobretudo na promoção da paz e da justiça “é uma condição necessária para a paz no mundo" (EG 250), como nos lembra o Papa Francisco.

No tocante ao diálogo com as várias denominações cristãs, a Igreja reconhece que as divisões internas são um escândalo para o mundo e contradizem a proposta de Jesus e prejudicam a própria pregação do Evangelho (UR 1). A falta de comunhão vai em direção contrária ao ensinamento de Jesus que pediu e rezou para "que todos sejam um para que o mundo creia" (Jo 17,21). Através do diálogo ecumênico busca-se despertar a consciência dos cristãos para a necessidade de recompor a unidade, valorizando e preservando a diversidade. Com isso abrem-se possibilidades para a construção de caminhos novos para a reconciliação entre as comunidades que, por razões históricas, acabaram se dividindo e separando.

O diálogo com o diferente, apesar de difícil e feito a passos pequenos, é necessário e torna-se frutífero para diversas as partes. O diferente deve ser visto, não como uma ameaça, mas como uma riqueza e uma possibilidade que se abre para a purificação e o enriquecimento mútuo, como atualmente propõe o Papa Francisco: "Nós, cristãos, podemos tirar proveito também desta riqueza consolidada ao longo dos séculos, que nos pode ajudar a viver melhor as nossas próprias convicções" (EG 254). 
Neste sentido, o encontro de Assis, em 1986, promovido pelo Papa João Paulo II quando se reuniu com os diferentes líderes das religiões mundiais para um momento de oração pela paz mundial, tornou-se um marco histórico e um sinal para o mundo. Naquele contexto, a questão central era a Guerra Fria que dividia o mundo em dois blocos e havia muitas guerras e focos de guerra provocados por esta divisão. Anos depois, caiu o Muro de Berlim e outras iniciativas de paz surgiram com mediação das religiões. Por exemplo, a paz em Moçambique (em 1992) depois de tantos anos de guerra e mais de um milhão de mortos, mediada pela comunidade cristã. Houve a aproximação entre Estados Unidos e Cuba, graças à ação do Papa Francisco. Recentemente, foi firmado o acordo de paz na Colômbia, também com apoio da Igreja. São alguns exemplos e sinais que indicam o papel que as religiões podem ter para a promoção da paz no mundo.

A Igreja Católica busca também o diálogo com as outras religiões que não confessam a fé cristã, em especial com os líderes judaicos e muçulmanos. Em suas viagens, o Papa Francisco faz questão que aconteçam encontros com os líderes destas religiões. O diálogo e a convivência harmoniosa deveriam ser parte integrante das religiões. A etimologia do termo Religião provém do latim religio, que significa "louvor e reverência aos deuses". A partícula re tem a função intensificadora sobre o termo que a sucede que é ligare. Assim "religião" significa “religar”, "reatar” ou "re-unir”. Daí é possível deduzir que a missão das religiões é religar ou restaurar os laços rompidos, seja com Deus, entre os seres humanos ou com a Criação.

No entanto, quando as religiões, ou parte de seus membros se fecham em suas verdades, absolutizando-as, acabam provocando conflitos e ameaças aos que lhe são diferentes. É o caso do Estado Islâmico, que pratica atos, considerados terroristas, apoiando-se em sua interpretação da fé islâmica; de grupos fundamentalistas que agridem as religiões afros ou realizam ataques homofóbicos ou agem contra os imigrantes. Em geral, os fanatismos têm sua sustentação nos matizes religiosos. Então, uma proposta de paz para o mundo envolve necessariamente também o mundo religioso. Vale recordar o que o teólogo Hans 
Küng afirmou sobre o que pensava sobre as religiões: "Não haverá paz entre as nações, se não existir paz entre as religiões. Não haverá paz entre as religiões, se não existir diálogo entre as religiões. Não haverá diálogo entre as religiões, se não existirem padrões éticos globais" (KÜNG, 2004, p. 17).

Neste tempo de fluidez, da "sociedade líquida" segundo Bauman (2001), em que o ser humano vive fragmentado, as religiões têm o papel de demonstrar que nem tudo é assim tão passageiro, e que há algo que é sólido e permanente. Por isso, vale o questionamento: que espiritualidade as religiões podem oferecer ao ser humano atual? Uma espiritualidade que seja capaz de responder aos desafios da vida, de quem caminha em meio às incertezas, aos desafios e problemas atuais.

A religião que é verdadeira dialoga com o mundo, com suas instituições e com as ciências, reconhecendo a sua autonomia, com as quais pode contribuir. Novamente podemos citar o exemplo do Papa Francisco que hoje é um interlocutor cujas palavras o mundo quer ouvir. Na Carta Encíclica Laudato Si’, sobre o cuidado da Casa Comum, ele oferece alguns percursos de diálogo sobre o meio ambiente, sobre problemas sociais e econômicos e o diálogo com as ciências, com o objetivo de colaborar para encontrar saídas da espiral de autodestruição em que o mundo se encontra (PAPA FRANCISCO, 2015, p. 133-162).

As instituições religiosas hoje podem estar em crise, mas não o seu carisma que precisa ser sempre atualizado aos novos tempos e novas realidades. Novas ressignificações são necessárias para que não se tornem ultrapassadas e ao mesmo tempo para preservar sua tradição herdadas e possam ter credibilidade em seu papel de diálogo com a sociedade.

É certo que a sociedade que se avizinha, o "tecnoliberalismo" como a define Éric Sadin (2017), modificará totalmente as relações humanas e certamente produzirá os lixos humanos jogados à margem da camada que viverá o bem-estar. Que função vão desempenhar as religiões diante destas massas marginalizadas de migrantes, favelados, desempregados, drogados, doentes de stress, depressão, 
câncer, e tantas outras formas de exclusão? Não pode querer que seja papel exclusivo das igrejas e religiões cuidar destas massas. Mas a estas pessoas é preciso que as religiões olhem com o olhar de Jesus, cheio de misericórdia e compaixão.

Às religiões restará sempre uma questão antropológica sobre a qual devem se defrontar: qual é a missão do ser humano na face da Terra e neste Universo ainda tão desconhecido? E haverá também aqueles que pregarão o fim das religiões sobre a face da terra. Porém, um mundo sem Deus se tornaria o mundo do caos, o retorno ao início onde as trevas pairavam sobre o abismo (Gn 1,2a). O ser humano é por natureza um ser religioso. O teólogo Karl Rahner (1967) afirmou que "o cristão do futuro ou será místico ou não será cristão”. Nós podemos parafrasear e dizer que o ser humano do futuro será religioso, será dialogante ou não será.

\section{Considerações Finais}

As instituições religiosas podem exercer uma função relevante nas sociedades democráticas contemporâneas como a participação de seus fiéis na esfera pública e pelo o exercício dos direitos civis e políticos no processo de fundamentação normativa das decisões políticas ou articulando a sensibilidade moral e os insights de solidariedade que foram perdidos na sociedade secular. Os discursos religiosos traduzidos em base racional de inteligibilidade podem auxiliar ao processo de legitimação política, a defesa dos direitos humanos e a realização da justiça social. Essa é a nova acepção que os diversos estudiosos e teóricos sobre a religião têm enfatizado em suas pesquisas acadêmicas (HABERMAS, 2012; BERNSTEIN, 2005; CASANOVA, 2013; MENDIETA \& VANANTWERPEN, 2011). Eles contrariam o anseio laicizante de restringir a atuação das instituições religiosas no processo de reconhecimento e luta por direitos nos Estados constitucionais.

O ressurgimento das religiões na esfera pública significa que os cidadãos religiosos devem participar da vida política e defender para todas as expressões de fé os direitos que a entidade religiosa hegemônica deseja que seja garantida para 
si. Nesse sentido, a defesa da ampla liberdade religiosa, o reconhecimento do pluralismo religioso e a necessidade de diálogo inter-religioso e ecumenismo são causas políticas e religiosas que devem fundamentar a formulação dos discursos religiosos nos Estados democráticos de direito. As diversas religiões têm que tomar para si o apelo de construção da paz social e a formação de cidadãos que saibam dialogar com distintas cosmovisões e projetos de vida.

A análise de Jürgen Habermas nos proporcionou a investigação sobre a possibilidade de reintrodução dos discursos religiosos à esfera pública e o reconhecimento que a secularização do Estado, na modernidade, não representou necessariamente a secularização da sociedade ou a aniquilação das religiões nas sociedades desenvolvidas. A possibilidade de diálogo entre a fé, o saber científico e a prática política permanecem entreabertos e atualmente urge a estruturação de projeto comum para uma sociedade mais justa e inclusiva. Esse projeto de sociedade se afasta da ideologia secularista, que denega a função dos discursos religiosos na esfera pública, e reafirma a necessidade de consenso sobreposto (overlapping consensus) entre as diversas formas de conhecimento.

A experiência católica de autorreflexão sobre suas doutrinas e preceitos mediante a realização do Concílio Vaticano II demonstrou a abertura ao mundo secular para a defesa da dignidade humana e o diálogo com as diferentes denominações religiosas.

A Igreja cristã, no exemplo apresentado da Igreja Católica e a experiência do Concílio Vaticano II, anuncia a esperança de uma sociedade mais igualitária e fraterna pelo reconhecimento da justiça e da necessidade de participação política para construção do Estado democrático de direito, em consonância com os direitos humanos. A Igreja se situa como mediadora de conflitos sociais e oferece ao espaço público a possibilidade de reconciliação entre aqueles que sofreram ofensas ou foram vítimas de formas de dominação social e o arrependimento daqueles que causaram sofrimento. Ela oferece o ato do perdão como sendo instrumento do exercício da capacidade de superação dos desníveis sociais e o saneamento de 
feridas.

A vida humana sem a orientação dos valores das tradições religiosas estaria fadada ao caos social e ao mundo de hostilidades. As religiões, como demonstrado na pesquisa, possuem o intuito de socialização e moralização dos indivíduos. As religiões esclarecidas cumprem a função social de formar cidadãos religiosos para a concretização do ideal de paz social e de respeito com a Criação. Além disso, elas motivam para a prática da solidariedade ao próximo marginalizado e discriminado. As religiões canalizam a capacidade motivacional para a ação social em prol daqueles que padecem na sociedade capitalista avançada.

Nesse sentido, concordamos com a orientação discursiva de Jürgen Habermas ao propor o diálogo entre o saber religioso e o científico como mecanismo de reconhecimento das diferenças sociais, entre indivíduos religiosos e não-religiosos, e a forma de inclusão de distintos saberes. A fé e a razão conciliadas pela prática discursiva podem colaborar para a realização da sociedade democrática que atua de forma tolerante e respeita os direitos individuais. Além disso, os discursos religiosos podem resgatar a sensibilidade moral de solidariedade e de preocupação com o outro. A racionalidade naturalizada pode orientar ao respeito às diferenças e a aceitação de escolhas distintas às doutrinas religiosas.

\section{REFERÊNCIAS}

BAUMAN, Zygmunt. A modernidade líquida. Rio de Janeiro: Zahar, 2001.

BERGER, Peter. O dossel sagrado: Elementos para uma teoria sociológica da religião. São Paulo: Paulus, 1985.

BERGER, Peter. The Desecularization of the World: Resurgent Religion and World Politics. Michigan: Wm. B. Eerdmans Publishing Company, 1999.

BERGER, Peter. Nach dem Niedergang der Säkularisierungstheorie. Centrum für Religion und Moderne, Münster, jul. 2013. Disponível em: <http://www.unimuenster.de/imperia/md/content/religion_und_moderne/preprints/peter_l._berger_nie dergang_der_s_kularisierungstheorie.pdf >. Acesso em: 02 jul. 2017.

Horizonte, Belo Horizonte, v. 15, n. 47, p. 828-854, jul./set. 2017 - ISSN 2175-5841 
BERNSTEIN, Richard J. The Abuse of Evil. The Corruption of Politics and Religion since 9/11. Malden: Polity Press, 2005.

BORTOLINI, Matteo. Found in Translation: Habermas and Anthropotechnics. The European Legacy, Basingstoke (etc.), v. 22, n. 5, 2017, p. 583-599.

CALHOUN, Craig. Afterword: Religion's Many Powers. In: MENDIETA, Eduardo; VANANTWERPEN, Jonathan. The power of religion in the public sphere. New York: Columbia University Press, 2011, p. 118-134.

CASANOVA, José. Exploring the Postsecular: Three Meanings of "the Secular" and Their Possible Transcendence. In: CALHOUN, Craig; MENDIETA, Eduardo; VANANTWERPEN, Jonathan. Habermas and Religion. Malden: Polity Press, 2013, p. 52-91.

CASANOVA, José. Public Religions in the Modern World. Chicago: University of Chicago Press, 1994.

DALAI LAMA. O Apelo do Dalai Lama Ao Mundo: A Ética é Mais Importante que a Religião. Áustria: Wals Benevento, 2015.

HABERMAS, Jürgen. Mundo de la vida, política y religión. Madrid: Editorial Trotta, 2015a.

HABERMAS, Jürgen. Verbalizzare il sacro: Sul lascito religioso della filosofia. RomaBari: Editori Laterza, 2015b.

HABERMAS, Jürgen. Nachmetaphysisches Denken II: Aufsätze und Repliken. Berlim: Suhrkamp Verlag, 2012.

JOAS, Hans. Die säkulare Option: Ihr Aufstieg und ihre Folgen. Deutsche Zeitschrift für Philosophie, n. 57, v. 2, 2009, p. 293-300.

KÜNG, Hans. Religiões do mundo: em busca dos pontos comuns. Campinas: Verus, 2004.

LUTHER KING JR, Martin. Um apelo à consciência: Os melhores discursos de Martin Luther King (Selecionado e organizado por Clayborne Carson e Kris Shepard). Rio de Janeiro: Zahar, 2006.

MENDIETA, Eduardo; VANANTWERPEN, Jonathan. The power of religion in the public sphere. New York: Columbia University Press, 2011.

MENDIETA, Eduardo. A Postsecular World Society? On the Philosophical Significance of Postsecular Consciousness and the Multicultural World Society, An Interview with Jürgen Habermas. The Immanent Frame, New York, fev. 2010. Disponível em:

<http://blogs.ssrc.org/tif/2010/02/03/a-postsecular-world-society/>. Acesso em: 02 jul. 2017. 
PAPA JOÃO II. Carta do Papa João Paulo II aos Bispos da Conferência Episcopal dos Bispos do Brasil. 9 de abril de 1986. Disponível em: $<$ https://w2.vatican.va/content/john-paul-ii/pt/letters/1986/documents/hf_jpii_let_19860409_conf-episcopale-brasile.html>. Acesso em: 31 ago. 2017.

PAPA FRANCISCO. Carta Encíclica Laudato Si’. Sobre o cuidado da casa comum. São Paulo: Paulinas, 2015.

RAHNER, Karl. Escritos de Teologia VI. Madrid: Taurus Ediciones, 1967.

RAWLS, John. Law of peoples. Harvard: Harvard University Press, 1999.

SADIN, Éric. Éric Sadin e a era do anti-humanismo radical. São Leopoldo, IHU ONLINE: Revista do Instituto Humanitas da Unisinos, São Leopoldo, 2017. Disponível em: < http://www.ihu.unisinos.br/569082-eric-sadin-e-a-era-do-anti-humanismoradical $>$. Acesso em: 02 jul. 2017.

SOUZA, Draiton Gonzaga de. Religião e sociedade pós-secular no pensamento de Habermas. Revista de Estudos Constitucionais, Hermenêutica e Teoria do Direito (RECHTD), São Leopoldo, n. 7, v. 3, set.-dez., 2015, p. 278-284.

UNGUREANU, Camil \& MONTI, Paolo. Habermas on Religion and Democracy: Critical Perspectives. The European Legacy, Basingstoke (etc.), v. 22, n 5, 2017, p. 521-527.

VEROVŠEK, Peter J. Habermas's Theological Turn and European Integration. The European Legacy, Basingstoke (etc.), v. 22, n.5, 2017, p. 528-548.

VITA, Álvaro. Sociedade democrática e tolerância liberal. Novos Estudos CEBRAP, São Paulo, n. 84, 2009, p. 61-81.

ZAMBAM, Neuro José; AQUINO, Sérgio R. Fernandes de. Tolerância: reflexões filosóficas, políticas e jurídicas para o século XXI. Revista da AJURIS: Associação dos juízes do Rio Grande do Sul, Porto Alegre, v. 42, n. 137, 2015, p. 365-385. Disponível em: <http://www.ajuris.org.br/OJS2/index.php/REVAJURIS/article/view/389>. Acesso em: 31 ago. 2017. 